\title{
LA INTEGRACIÓN COMO EPISTEMOLOGÍA: ESBOZOS DE LA TEORÍA Y POÉTICA DE ÉDOUARD GLISSANT
}

\author{
INTEGRATION AS EPISTEMOLOGY: SKETCHES \\ OF THE THEORY AND POETICS OF ÉDOUARD GLISSANT
}

\author{
Nibaldo Acero \\ Pontificia Universidad Católica de Chile. Santiago, Chile \\ nibaldoacero@gmail.com \\ Rodrigo Marilef \\ Universidad Central de Chile. Santiago, Chile \\ rodrigo.marilef@ucentral.cl
}

\begin{abstract}
Resumen: Aquí es presentada una lectura integracionista, metodología articulada por el filósofo y poeta Édouard Glissant, con la cual analizaremos un poema de su propia autoría, "1953", compaginado en Sol de la conciencia (2004). Tal gesto metacrítico apostará por explicitar, adentrarse y vivificar los conceptos que activan una filosofía de integración cultural emancipadora. Epistemología que suscita una comprensión del "Todo-Mundo" a partir de la superación de todo apartheid ubicado en el espacio del conocimiento. Pensamiento desde el cual apostamos por una "epistemología poética”, ampliando la teoría de Glissant.
\end{abstract}

Palabras clave: Poética de la relación, poética de lo diverso, opacidad, archipiélago.

\begin{abstract}
This article presents an integrationist reading, a methodology articulated by the philosopher and poet Édouard Glissant with which we will analyze a poem by the same author, "1953", belonging to his book Sol de la conciencia (2004). This metacritical gesture will specify in detail, study in depth and bring alive the concepts that activate a philosophy of emancipatory cultural integration. This is an epistemology that demands an understanding of "The Whole World" which begins with the overcoming of apartheid located in the space of knowledge. It is a way of thinking from which we can lay stake to a "poetic epistemology" by amplifying Glissant's theory.
\end{abstract}

Keywords: Poetics of relation, poetics of the diverse, opacity, archipelago.

Recibido: 09.10.2014. Aceptado: 21.04.2015. 


\title{
Introducción
}

\begin{abstract}
Otra vez repito que no soy un crítico imparcial y objetivo. Mis juicios se nutren de mis sentimientos, de mis pasiones... Estoy lo más lejos posible de la técnica profesoral y del espíritu universitario.

José Carlos Mariátegui, Siete ensayos de interpretación de la realidad peruana
\end{abstract}

$\mathrm{E}^{\mathrm{s}}$ FRECUENTE COINCIDIR CON estudios postcolonialistas, subalternistas, y otros, cuyo ánimo de (pseudo) descolonización del saber ha configurado una impoluta máscara de producción de conocimiento, a estas alturas legitimada e institucionalizada. Estudios, investigaciones, reflexiones que debido a su cientificismo a ultranza y su deseo de validarse en el mercado académico han travestido sus más loables proyectos de descolonización del conocimiento, implicando un sistema de comprensión puramente occidentalista ${ }^{1}$ sobre todo objeto, texto o sujeto. De hecho, en la práctica, más de algún discurso marxista ha servido de velo para un ejercicio puramente erudito que intenta validarse éticamente, sin mover un solo dedo más allá de la escritura, y muchas veces ni siquiera esto ${ }^{2}$. Poco a poco comienza a

\footnotetext{
${ }^{1}$ No desconocemos la progresiva occidentalización que ha vivido el mundo contemporáneo, proceso en el cual la reflexión, discusión y articulación del poder y del conocimiento, se encuentran emplazados. No desconocemos tampoco el vínculo de Occidente y su voluntad de sujeción sobre otras expresiones culturales. El asunto entonces es adentrarnos en la posibilidad de una mirada, y especialmente una práctica que, asumiendo la tradición occidental (porque tampoco caeremos en una "ingenuidad ideológica”, si no, ¿̇desde dónde hablamos, nosotros, los autores, y el propio Glissant?), permita el desarrollo de un discurso y una praxis que al menos tenga la voluntad de descentralización. Víctor Manuel Ávila Pacheco se pregunta si puede existir una poética descentralizada, que permita imaginar categorías geo-historicas para un mundo no imperialista. Su respuesta es positiva, pero advierte que su desarrollo no es una labor sencilla. Esa es la tarea que, creemos, asume Glissant: "reconstruir los lugares, como espacios epistemológicos, sin desconocer la ubicación geopolítica y el cuerpo político del sujeto que habla" (Ávila Pacheco, 2010).

${ }^{2}$ Nos referimos básicamente a ese marxismo que ha vulgarizado la teoría marxista, proponiendo un dogma pétreo, que ha terminado por institucionalizarse. Marxismos que se escudan en presupuestos metodológicos, aparentemente revolucionarios, para no decir nada, o lo que es peor, para hacer nada, olvidando el principio de la onceava tesis contra Feuerbach: transformar la realidad. Marxismos, en fin, de intelectuales que terminan justificando todo statu quo, por miedo a que realmente todo cambie. También nos referimos a ciertas asunciones que no toman en cuenta los contextos propios. Néstor Kohan ha dicho, a propósito del pensamiento de Marx, que "la explosiva y avasallante expansión que experimentaron sus ideas en el (nuestro) Tercer
} 
ser sospechoso que se enarbolen desde la academia ${ }^{3}$ tantos lábaros discursivos, defensores de quienes han padecido el servilismo colonial. Causa suspicacia esta desesperación por ser interlocutores de subalternidades o registradores/archivadores del desamparo que se sufre en las fronteras. En su afán de ineluctable poder, parte importante de los intelectuales de esta parte del mundo -ya civilizados- han tomadas prestadas y han blandido alabardas liberales, homogeneizando astutamente el discurso, perpetuando sigilosamente un acercamiento al saber de forma vertical, hegemónica y tendenciosa. Debido a este discurso institucionalizado, tratar problemáticas de diversidad, etnicidad o de interculturalidad en la universidad, puede llevar la discusión directamente a una seductora inercia, la que gracias a una estratégica nomenclatura, parapetará una crítica hermética y poco combativa, mayormente pendiente de defender los intereses del poder que la subordina, que de denunciar los abusos de una sociedad (Said, 2006, pp. 151, 153, 158). Ante este panorama desalentador en lo propiamente crítico, casi nos vemos obligados a sondear otras formas de comprender la cultura y la sociedad para sustentar una transformación de aquellas y no solo promover una reflexión a modo de ejercicio intelectual. Una de aquellas epistemologías es la que surge del pensamiento de Édouard Glissant. Filosofía y poética devenidas de la experiencia vital, de la conciencia de clase y

Mundo estuvo mediada por un enfoque que lo colonizaba de antemano, reduciéndolo y subordinándolo a un paradigma marcadamente occidentalista y eurocéntrico" (Kohan, 2003).

${ }^{3}$ Es complejo sostener un proyecto de independencia crítica o de libertad intelectual en las plataformas académicas de Latinoamérica. Pero quedémonos en Chile y concentrémonos en los estudios literarios y culturales. Los académicos que gozan de cierta autonomía, de un espíritu crítico genuino, al imbricarse en los sistemas de poder, comúnmente vinculados a la universidad, y salvo memorables y no abundantes excepciones, acaban modelando sus ideologías y sosegando los discursos y, lo que es más peligroso para el conocimiento, alienando en mayor o en menor grado la práctica misma de una crítica, despegándola del mundo. Lo que decimos no es nuevo, desde Auerbach hasta Bhabha, pasando por Said, Saer y Frye, entre otros, ha existido una conciencia crítica capaz de verse muchas veces a sí misma como una actividad que, en la aspiración de construir su autoridad y circuitos de poder, abandona una intervención en la sociedad misma, al punto que son múltiples las renuncias epistemológicas, las que delatan una consolidación de aquellos ranchos de poder en desmedro de la emancipación de una práctica y de sí mismos como intelectuales. Comprendemos que esto puede ser muy discutible, sobre todo desde la academia, mas defendemos este ejercicio de abrir la discusión en torno al escaso o supuesto compromiso de la crítica con su contexto histórico. 
la sensibilidad de un hijo de campesinos, descendiente directo de esclavos que, en los años treinta, también es testigo de la lucha independentista de Martinica. Intelectual que estudia en París y que vuelve a Las Antillas entrecruzando identidades y mundos, poeta que se (auto)forma sobre prácticas discursivas radicales, como las de Aimé Césaire, las de Fanon o las del poeta africano Léopold Sédar Senghor, pero que es capaz de articular un pensamiento propio, el que aglutina poéticas y gestos metodológicos revolucionarios. Pensamiento a partir del cual es posible articular una epistemología poética, activando una sinapsis procesual del conocimiento, incluso tolerando la posibilidad de una disidencia por la insistente visibilización de las diferencias, lo que refrenda su compromiso con la diversidad y libertad. Filosofía que asume los riesgos de la teoría y práctica de la integración y la reciprocidad entre pueblos, con todas las complejidades de lo que ello implica, aquilatando el peso de la historia e instalando un deseo de intervención, de una crítica que no solo identifique problemáticas o teorice geopolíticamente al Caribe o se fascine con la reformulada violencia colonial, sino que asuma el riesgo de apostar por un proyecto complejo, el que repiense y difracte los conceptos de identidad, de lengua y nación.

\section{Pensamiento archipiélago: caos, paisaje y palabra barroca en el Todo-Mundo}

Yo escribo en presencia de todas las lenguas del mundo GLISSANT

Creemos que es absurdo definir una graduación conceptual de la teoría global de Glissant ${ }^{4}$, por ese carácter emancipatorio no jerárquico por el que apuesta, por ello nos adentraremos primeramente en uno de sus conceptos más resistidos: el caos. Escribe Glissant:

${ }^{4}$ La filosofía del martinicano no carece de detractores, quienes frecuentemente advierten una insostenibilidad teórica en su planteamiento, inconsistencia conceptual frente a teorías, en el papel, de mayor impacto e injerencia histórica, incluso tildándolo de "autor menor". Aquí se avizora el primer cuestionamiento duro a la teoría de Glissant: la no definición de una clara némesis y el arrojo que despliega al difractar un pensamiento binario -kantiano-, no exhibiendo pleitesías estructuralistas ni un 
Entiendo por caos-mundo [...] la colisión, la intersección, las refracciones, las atracciones, las connivencias, las oposiciones, los conflictos entre las culturas de los distintos pueblos de la totalidad-mundo contemporánea. Consecuentemente, la definición o mejor el enfoque que propongo de esta noción de caos-mundo es muy precisa: se trata de la mezcla cultural ${ }^{5}$, que no consiste en un mero "melting-pot", en virtud de la cual la totalidad-mundo se ve hoy materializado (2002a, p. 82).

Si bien Glissant explicita que el término lo extrapola desde la física, este lo instala y echa a andar en el campo de la cultura, relacionando esta teoría con "el comportamiento impredecible de la relación entre las culturas" (2002a, p. 85). La carencia de soberbia ante el conocimiento, se complementa con una fascinación y apertura científica, la que despliega integracionista, superando el reduccionismo propio de occidente. Este caos es sustrato de la figura del archipiélago, que es como el mismo Glissant consigna a su pensamiento. El caos propicia la facultad de impredecibilidad de una epistemología integracionista, la que desactiva un sistema determinista, reduccionista, pretendidamente objetivista en su proceder, fijo en sus apreciaciones, clasista, racista, en fin, el festín habitual en parte de la producción intelectual occidental o que aspira a serlo. Este caos, caracterizado "no tanto por el desorden sino por la imprevisibilidad" (Sancholuz, 20022003, p. 3), también se relaciona con su concepto creolización, concepto antropológico que dice de un proceso de mestizaje consciente de sí mismo, donde incluso los elementos olvidados de una identidad se vivifican a tra-

discurso técnicamente politizado. Su metodología más que limitar una lectura a las luchas de clases e inmediatamente desactivar al texto en favor de un análisis estrictamente político - considerando al análisis un "acto" por sí mismo-, integra el análisis marxista a un sistema más amplio y complejo, el cual es capaz de suturarlo y tensarlo a otras lecturas.

${ }^{5}$ Creemos que la mejor traducción para el término melange culturel del texto original, no es la de mezcla cultural, sino más bien de integración cultural, sobre todo porque el propio Glissant, a continuación, remarca la diferencia del concepto de un mero "melting-pot". El término "mezcla», mescolanza o mestizaje no dejan de ser una evidente reducción de la discusión ante la complejidad que reviste tratar de integración, la cual urge, como seguiremos viendo, de procesos de transculturización más extensos e intensos y que develan lo brutal que ha sido no solo su historia, las cicatrices y laceraciones vivas aún de las colonias, sino esta porfía de intentar ser el interlocutor de una cultura siempre a modo de etnógrafos críticos. Se intenta con ello suturar una herida con el mismo puñal que fue provocada. 
vés de la memoria: "La creolización no permite comprender sino más bien intentar aprehender lo que pasa en el mundo. Intentar penetrar y descubrir la creolización del mundo, es comenzar a luchar contra la estandarización generalizada que alcanza a la economía, a lo social, a la cultura" ${ }^{6}$.

Continuamos. "Creemos en la palabra de los paisajes" atestigua Glissant en su texto "Las Américas barrocas”, será este el segundo concepto con el que nos vincularemos. La geografía en Glissant es penetrante, adquiere una incidencia relevante en la construcción de la realidad, en la interpretación y análisis de la misma. El paisaje es resignificado en sus poéticas, dejando de ser mera escenografía permanente en el fondo de la cultura. El paisaje se torna protagonista, como la naturaleza que se introduce en los vestigios de una ciudad ancestral. Se explicita imprescindible, indomable, y aun cuando se le intente escamondar, es caótico, pues no respeta preestablecidas normas ni se extiende a partir de un sistema determinado. Por ende, el paisaje sería la materia de la sociedad y de la historia misma: "existe [en Glissant] también una relación fuerte entre el paisaje y la Historia, en este caso, con la huella del paisaje como historia propia del hombre" (Mercier, 2012, p. 184). No sería otro ámbito o sólo un soporte invisible, sobre todo si recordamos que el lugar de enunciación (y de origen) de Glissant es un archipiélago: "Apasionadamente vivir un paisaje. Despejarlo de lo indistinto, esculcarlo, encenderlo entre nosotros. Saber lo que en nosotros significa." (1969, p. 238). El paisaje que lo rodea y lo integra es el sustento en la articulación decidida de una identidad, cuya historia intenta ser reformulada y rehecha proféticamente, es decir, relaciona anacrónicamente el sentido de futuro, presente y pasado como un solo entramado comunitario, histórico y alegórico. El paisaje es el texto que a base de muertos, memoria y naturaleza mutante, se ha ido escribiendo, texto que es capaz de soportar intensas y diversas conexiones de corte político, geográfico, cultural, social y personal. Escribe Glissant:

Está claro que nuestra relación con el paisaje es algo que no puede imaginarse si no se tienen en mente este tipo de imágenes. Cuando estaba

\footnotetext{
${ }^{6}$ Entrevista a Glissant, "Nous sommes tous des créoles", por Thierry Clermont y Odette Casamayor (citado por Sancholuz, 2002-2003). Superar las estandarizaciones o globalizaciones culturales, identitarias, es aún una conexión inmediata y comprometida que establece Glissant entre su sociedad y la transformación de aquella.
} 
en Martinica, podía observarlo en las casas. Está la cima tradicionalmente, todas las casas de los amos estaban allí, porque es donde hay más aire fresco, y todas las casas de los esclavos se ubicaban más abajo, no sólo por el aire, sino también por los huracanes, porque toda la tierra desciende a las casas de los pobres. $\mathrm{Y}$ ahora puede verse a los martiniqueños conquistando la cima, lo que sociológicamente es muy importante, pues esta relación significa que el estatus no cambia únicamente por hacerse rico y comprar una casa. Más importante que esto es la relación con el paisaje, que cambia; tú cambias. Yo no lo llamaría un modelo para la humanidad, sino más bien un modo de estar en el mundo (2006, p. 31).

En el paisaje es donde se materializa la relación que da nombre a una de sus poéticas. Esta relación es memorial y a la vez física, identitaria, es el movimiento que configura la cultura y donde se escenifica la integración. Esta relación crea y a la vez reestablece los vínculos entre el paisaje, la identidad y la historia (personal y colectiva); los vínculos se propagan, se multiplican sin una aspiración unitaria. También es inevitable concebir esta relación con la geografía propia del Caribe, con el paisaje del lugar de enunciación y origen de Glissant: los archipiélagos que curten una memoria y un discurso. Geografía desperdigada, no unitaria, donde podemos encontrar un sustento fértil para dos de sus poéticas: la de la Relación y su poética de la diversidad. Estas, integradas a la figura del archipiélago, suturan un pensamiento que no cesa en su proyecto de emancipación epistemológica e integracionista:

Antaño, simultáneamente con los libros fundacionales a los que me he referido y con todas las literaturas con las que procedían, el pensamiento -el que yo llamo pensamiento de sistema- ha organizado, examinado y proyectado esos efectos lentos e imperceptibles entre las lenguas; ha previsto y puesto en perspectiva ideológica el movimiento mundial que él regentaba legítimamente. Hoy, este pensamiento de sistema que, de buen grado llamo "pensamiento continental", ha flaqueado al no considerar el no sistema generalizado de las culturas del mundo. Otra forma de pensamiento, más intuitiva, más frágil, amenazada, en sintonía con el caos-mundo y con sus impredecibilidades, se desarrolla, sustentada quizás por las ciencias humanas y sociales, pero deslizada hacia una visión de la poética y del imaginario del mundo. Califico a este pensamiento como "archipiélago", un pensamiento asistemático, inductivo, en la exploración de la impredecibilidad de la totalidad-mundo y conciliando 
escritura con oralidad y oralidad con escritura. Los continentes, me parece, se tornan archipiélago, al menos vistos desde fuera (2002a, p. 45).

Esta sostenida, armoniosa y caótica (a la vez) relación entre los elementos de la totalidad-mundo es posible gracias a un pensamiento "archipélico", que es un "pensamiento no-sistemático, cuya forma es intuitiva y frágil, y deriva de una visión poética y de un imaginario del mundo" (Boyer, 2009, p. 20), y que a pesar de su fragilidad, es lo suficientemente vasto y fraterno para religar culturas, tradiciones, imaginarios. Cabe señalar, que el pensamiento archipélico de Glissant se materializaría como palabra barroca, lo que delataría un proyecto de integración estética y científica. Volveremos a este punto más adelante. Otra de las coherencias apreciables en esta teoría es que, más que desechar una tradición en favor de otra, procura una ambivalencia (opacidad) en la enunciación política, una negociación imaginaria, como la llama Homi Bhabha, de "instancias contradictorias y antagónicas" (44-46), las que articulan a la postre una crítica integracionista, conciliatoria pero tensa, caótica y diversa, performática de diferencias, como un archipiélago cultural en permanente movimiento. Y es que el mar del Caribe no unifica, no es el mar Mediterráneo, que sí fuerza una unidad, escribe Glissant. El mar del Caribe "difracta" (Glissant, 2002a, p. 16), lo que ha ayudado a construir una multiplicidad, heterogeneidad que lejos de ser un escollo a nivel cultural o identitario o intelectual, ha sido una gran posibilidad para comprender el mundo complejamente, problematizando las teorías y poéticas que están en líneas neoliberales y que agostan las discusiones al determinarlas "disciplinares”, por ejemplo. La geografía permite apreciar y convivir con toda la diversidad existente, es sinécdoque del Todo-Mundo.

Desde aquel paisaje cercano y omnipresente al martinicano, pende una orografía ideológica en medio del Caribe. Una tierra inquieta, que es y no es isla ni continente, y que observa el Todo-Mundo en su potencialidad, integración y carestía. Geografía caótica y ambigua que sería la matriz de la opacidad con la cual Glissant invita a leer la realidad, a través de una mirada antiimperialista del mundo, cuyo afán es fragmentar, por ejemplo, el monolingüismo y toda clase de imaginarios hegemónicos: "Que la opacidad, la nuestra, si la hay para el otro, y si para nosotros la hay del otro, no cierre vistas, cuando ocurra, que no tenga vistas al oscurantismo ni al apartheid, 
que sea para nosotros una fiesta y no un espanto" (2006, pp. 31-32). Opacidad que es un derecho a disentir (he aquí la tolerancia de la disidencia), lectura desarticuladora ante dominantes discursos que por siglos instalaron una discusión disimétrica entre un blanco y un negro, entre un esclavo y un amo. De esta manera, la opacidad se integra a una epistemología capaz de mirar la realidad y al ser humano en su real dimensión, con sus luces y sombras, sin apelar a una "transparencia". La opacidad es metáfora de la resistencia a esa luz todopoderosa del Occidente dualista (luz = verdad y conocimiento; oscuridad = falsedad e ignorancia (Cfr. Marramao, 1998)), de aquella luz totalitaria enceguecedora y omnipresente que ha impedido apreciar los trazos de oscuridad que le dan a un objeto cierto volumen y un determinado espacio en el Todo-Mundo. Atributos que construyen un sujeto, un texto u objeto en único y original. Luz quemante e inmóvil que, enfrentada a un sujeto, objeto o un texto, una Historia, pierde la visibilidad íntegra y recibe mayormente de vuelta un reflejo, no acusando recibo de las sombras proyectadas ("Exigimos el derecho a la oscuridad", declama Glissant en El discurso antillano). Y aun cuando esta luz impide una mirada íntegra e integradora de la realidad, esa es la visión que se institucionaliza, oficializa, incluso se naturaliza. El Caribe, constituido a partir de su archipiélago rizomático, es sustento de una ambigüedad que Glissant defiende. El mundo y su diversidad es un archipiélago que debería ser comprendido como Glissant comprende la integración en Las Antillas, bajo preceptos de diversidad, identidad y relación, de reciprocidad. El archipiélago no ostenta la estabilidad y lo unitario de lo continental. El paisaje archipiélago se despliega performático en diferencias y gracias a su insular geografía se transforma en cartografía de potencial integración, de inclusión cultural, social, de solidaridad.

A partir de estas poéticas, las conceptualizaciones devenidas desde la teoría y de la crítica literaria, por ejemplo, deberían guardarse de ser edificantes, tajantes o totalizadoras. ¿A qué tanta cientificidad académica, a qué tanto discurso globalizante y universalista en su enunciado, pero ideológicamente local en su enunciación? Podríamos preguntarnos ¿A qué tanta colonización del saber en pos de una hipotética descolonización? ¿Por qué estas máscaras discursivas? Al respecto, escribe el martinicano: "El científico, el técnico, que hoy no tienen la obsesión de esta necesidad de compartir de manera planetaria sus conocimientos, son ciegos; el poeta 
que no vive del estremecimiento del mundo, es un lisiado" (Glissant en Bansart). Creemos que los estudios culturales, literarios, deberían hacer un "esfuerzo" (Glissant, 2005) por explicitar incluso el margen de error entre tanta impredecibilidad, particularidad y divergencia habitantes del TodoMundo, así se evitarían por ejemplo la evidencia de ciertos apartheid en el conocimiento, puesto que al absolutizarse en lo disciplinar, al encapsularse y despegarse de su contexto histórico, más bien aspiran por configurar un conocimiento monodisciplinar (a lo más vinculado con los Estudios Culturales y una que otra noción filosófica, lingüística o sociológica). Un saber solo para sí mismo, que prescinde de otros saberes y conocimientos. Y que se hace a sí mismo prescindible.

Volviendo a la palabra barroca, es en ella donde subyacen las fuerzas de alteridad e identidad en permanente movilidad, divergencias y relación. Atraviesan también por ella la música del carnaval, los gritos de una polifonía castigada, la violencia y el misticismo. La intertextualidad que vincula de punta a cabo una tradición literaria:

La historia del Caribe es una historia balcanizada, donde las islas a pesar de su proximidad han estado separadas por los colonizadores y sus lenguas. Pero a pesar de estas diferencias los escritores caribeños tienen estilos coincidentes porque el barroco hispánico marcó toda la estructura del lenguaje, la forma de contar. El Caribe está descubriendo eso y que la diferencia de idioma no es una barrera.

La balcanización del Caribe no es solo geopolítica, también es idiomática, diversidad lingüística que si bien se nutre de divergencias, produce una integración cultural, donde la palabra barroca sobrevive como estructura identitaria. De este fenómeno, que integra geografías y lenguas, y cuyo resorte es la palabra barroca, hay sólo un paso para la integración de géneros, también para la absolución de límites y escisiones formales, pero también de las raciales, desintegrando los imaginarios coloniales e integrando sensibilidades "multilingüísticas", al punto que el propio Glissant, un descendiente directo de esclavos, escribe "a pesar de todo, éramos libres de mirar

${ }^{7}$ Entrevista a Glissant, en el ciclo de conferencias de "Literatura y destierro", organizado por la Casa refugio de escritores Citlatéptl, Ciudad de México, publicado en la revista ¿Cómo cambiar el mundo? En Sancholuz (2002-2003, p. 8). 
a Faulkner a los ojos, de ir con él a donde quisiéramos llegar”. Faulkner, escritor estadounidense, granjero, símbolo del amo y del sistema de plantaciones, recibe de Glissant palabras de admiración. La visión y apuesta del martinicano se adentra en su propia historia, ampliando su propio radio de deliberación y de sensibilidad.

A los anteriores elementos y conceptos, integramos ahora la desmesura, que, al igual que el caos, es más bien un sustrato de la figura del paisaje (y de la(s) lengua(s)):

Desmesura no porque resulte anárquica, sino porque carece de la pretensión de profundidad, la pretensión de la universalidad, aspira únicamente a la diversidad. [...] Esta desmesura es la apertura total, que no es sino el todo-mundo. La literatura ha seguido esa senda. Y resulta completamente evidente que las literaturas francófonas se sitúan ahí, en la desmesura de la desmesura, literaturas que no aspiran a la negación que comporta el barroco, ni a la profundidad del clasicismo, porque experimentan la diversidad y la desmesura del todo-mundo. Si fuera un erudito, diría que he pasado de la medida de la medida a la desmesura de la medida, a la medida de la desmesura, a la desmesura de la desmesura y estaría formulando un quiasmo (2002a, pp. 94-95).

El concepto de integración en Glissant se activa gracias al rizoma de Deleuze y Guattari ${ }^{8}$, integración que, como fenómeno, es inquieta y no ceja en su deseo de emancipación ${ }^{9}$. Este deseo desborda los marcos regulatorios y

${ }^{8}$ Escribe Glissant respecto al "rizoma": "Raíz múltiple, extendida en redes en la tierra o en el aire, sin que ningún tronco intervenga como predador irremediable" (Glissant, 1990, p. 235). Como hemos señalado, la apertura científica de Glissant es una actitud ante el conocimiento que se despliega integracionista, superando el reduccionismo propio del cientificismo de Occidente. La ciencia, entiende Glissant, se construye rizomáticamente, emancipando las posibilidades del conocimiento, resistiendo así el "inmovilismo y univocidad de lo Uno, la movilidad de lo diverso y la múltiple singularidad de lo Único, al Conocimiento y a la Globalización, la Opacidad y lo Fragmentario" (Maignan-Claverie, 2003, p. 343).

${ }^{9}$ Entre las recensiones, ya mencionadas, que los estudios culturales han enfocado sobre la obra de Glissant es frecuente coincidir con una crítica que considera su obra "despolitizada", en contraste con el activismo político de Cesaire. Tampoco es difícil prever que los ataques argumenten que tal emancipación teorizada no generó más que buenas intenciones. Esto es bien discutible, pero tampoco es el lugar para ejercer esta discusión. Sin embargo, aquí nos vinculamos por sobre todo con la filosofía integracionista de Glissant y la ampliamos, como anunciamos al principio del ensayo, pero también con su propia experiencia vital, como sujeto marginado, consciente de 
conservadores de la literatura. Pero los mecanismos de esta integración no solo son asistémicos, sino que en su proyecto de emancipación inician una sinapsis analítica e interpretativa, una suerte de programa comprensor que en vez de explorar los bordes y asentarse -y he aquí la desmesura- se lanza, profundiza y expande sin parangón las relaciones y proyecciones de un pensamiento, de una literatura, manifestando un proceso de conocimiento que roza lo anárquico en sus ganas de libertad.

\section{Análisis de "1953"}

Para aplicar la teoría de Glissant en el análisis de un poema de su propia autoría, consideramos que con cada concepto tratado aquí deberíamos relacionarnos movedizamente, sin una ubicación lectora permanente, permitiendo el dinamismo de diversas y paralelas miradas críticas. No subordinando conceptualización alguna, sino relacionando "caóticamente" teorías y estéticas, no para provocar, sino para emancipar la comprensión y desbordar un análisis puramente occidentalista, gran parte de los cuales están anclados en la distancia crítica, en una improductiva objetividad, en la autoconvicción vacía de estar "produciendo conocimiento", el que rara vez sirve para transformar o hacer frente a las problemáticas sociales que se viven y sufren o al menos educar para resistirlas. Por su parte, Glissant, y lo señalamos, supera los apartheid dentro del campo del conocimiento, lo que metodológicamente es revolucionario, y en su ánimo de difracción, suscita la problematización de todos los conceptos arraigados como larvas inmóviles en la tradición. Esta lectura apuesta por una comprensión emancipatoria del texto, en base a su filosofía y poéticas; por medio de la figura del archipiélago y la opacidad, de la palabra barroca, del caos: ambigüedades, luces y sombras, nos permitirán abrir de par en par las puertas de su (la) poesía. "1953”:

su contexto y clase que, de regreso en Martinica, incluso adscribe al Frente antillanoguyanés, demostrando con ello, y con varios otros gestos, su compromiso político libertario. 


\begin{abstract}
El árbol daba palabras
escribía a la mañana

el viento le respondía.

Estaba quieto el camino

el saber, en otra parte;

tras la palabra hay un fruto

en que duermen los que saben

al fin con sueño inocente.

Falta el viento a quien es árbol;

quien duerme olvida el camino
\end{abstract}

En el primer verso es delatada una relación: el árbol y la palabra (como fruto ${ }^{10}$; una relación de creación (transcreación) que se vincula al sexto y noveno verso. La relación poética entre árbol y fruto, entre otros vínculos paridos en el poema, sustenta $a$ la palabra que emancipadamente crea el Todo-Mundo. Esta relación árbol/fruto/palabra también despliega una metáfora del poeta con su obra; de la oralidad troncal con la escritura. Fruto y árbol son frecuentes en un paisaje, sea este caribeño o europeo, son parte minúscula y relevante de la construcción de toda una geografía. Por otro lado, e incitados por la opacidad glissantiana, podríamos reconocer la no dependencia del fruto al árbol, ni del árbol a su fruto. Así, la relación entre ellos se construiría caótica y armoniosa, complementaria, resignificando con esto un sentido anticolonial de acceder y de ser en el mundo, del sentido lógico y deductivo del pensar occidental. Pero también la podemos leer como una relación de reciprocidad. Movámonos nuevamente al primer

${ }^{10}$ En la lógica de ampliación epistemológica (y metodológica) de Édouard Glissant, podemos también vincular el gozne que el martinicano ya establece en el poema, entre la palabra (barroca) y el fruto, comparándolo con algunos lienzos de pintores barrocos del s. XVI, en especial los de Caravaggio. En los lienzos del pintor milanés, por ejemplo, las fuentes rebosantes de frutas, despliegan en sí mismas trazos de oscuridad y de luz, donde gracias a este efecto tensional -de contrapunto- se realzan los diferentes colores que constituyen la obra pictórica. Es importante señalar que parte de las frutas representadas, están agrietadas o sufren de ciertas pestes, no representando así la idealización renacentista y siendo a la postre considerados parte de una pintura profana. Alegóricamente, encontramos en los lienzos barrocos de Caravaggio las bases teóricas de Glissant: la opacidad (contrapunto: tensión del blanco y el negro, la explicitación de las diferencias, de las sombras de los elementos), el reconocimiento de la diversidad, la integración, la desmesura y la materialidad en desmedro de una idealización y del preciosismo estético y moral del Renacimiento. 
verso: "El árbol daba palabras". La palabra creadora (barroca) es creada por la naturaleza, nace de un árbol/poeta, es comparada con el oxígeno, con el aire emanado que se transforma en viento: "escribía a la mañana/ el viento le respondía”. La palabra es la que relaciona intensamente lo físico, la geografía y el paisaje con el tiempo. Relaciona el árbol a la mañana, decíamos, pero también lo devela como un dispositivo que deconstruye la visión clásica judeo-cristiana del "árbol del conocimiento", aquella historia bíblica del Génesis que ubica al conocimiento como algo negado a Adán y Eva: el pecado original como la voluntad de saber, de adquirir el conocimiento censurado. En Glissant, la palabra devenida del árbol se hace viento y germina de poesía la realidad, da respiración, da vida a los seres vivos, como si fuese un fruto que sostenidamente se desintegra y regenera. El momento donde se re-crea el poema es la mañana, el amanecer, esto sigue dando un sentido de relación a los elementos ocultos del poema. La mañana, el amanecer, relaciona la noche con el día, por ejemplo. Se da en el poema un momento de creación articulado por la palabra: otro elemento frágil e impredecible. Pero, ¿cómo sería capaz la palabra de crear/relacionar el Todo-Mundo? El Todo-Mundo quizás podría ser considerado como un gran texto místico y físico, donde la poesía se expande y vincula cada uno de los elementos entre sí. O el Todo-Mundo, al ser un entramado de relaciones caóticas, originales e irrepetibles (Glissant, 2002a, p. 82) se acercaría al concepto de poesía, en tanto creación de inagotables conexiones entre códigos, símbolos, figuras y tropos. $\mathrm{O}$ esta relación palabra $=$ creación, la podríamos también vincular con la, nuevamente mencionada, tradición judeo-cristiana: "En el principio era el Verbo, y el Verbo era con Dios, y el Verbo era Dios. Este era en el principio con Dios. Todas las cosas por él fueron hechas" (Jn. 1:1-3). O podríamos relacionarla con una tradición precolombina, el Popol Vuh: "iHágase así! iQue se llene el vacío! iQue esta agua se desocupe, que surja la tierra y que se afirme! -así dijeroniQue aclare, que amanezca en el cielo y en la tierra. No habrá gloria ni grandeza hasta que no exista la criatura humana, el hombre formado -así dijeron" (18). Sin embargo, mucho indicaría que en base a la teoría de Glissant, la palabra no fundaría cosa alguna, al modo del conquistador que, luego de masacrar nativos, consigna un nombre para una determinada región. La creación en Glissant no sería un concepto que lleve en su ADN una fuerza colonizadora ni vertical ni dominante sobre un "otro". La creación para el 
martiniqueño contemplaría la poética de la relación, pero también la de la diversidad. Una capacidad de aceptación y de respeto a la multiplicidad, que no tiende a la fusión y, finalmente, a la alienación de diferencias. Esta creación estaría lanzada a la construcción enérgica de la totalidad-mundo a partir de la poética de la Relación y la armonía de la diversidad y el caos. Existen otros elementos con los cuales relacionarse en el poema: la figura del camino instalada en dos ocasiones, además con el sentido del verbo sustantivado, "el saber", en relación a la conjugación verbal: "los que saben"; comprendidos todos estos términos en cuatro versos distintos. El camino ha sido metáfora histórica del paso de la vida, manipulado tópico literario, aquí explicitado como concepto totalizador, como parte de esa familia de términos occidentales que han tendido estratégicamente a la unidad, homogeneidad y sistematicidad (verdad, bondad, belleza, etc.). Dice el poema: "Estaba quieto el camino". Considerando ya al camino como un elemento occidental, el gesto de hablar en pasado profetizaría el arribo del europeo, quien desembarcaría posteriormente, trazando caminos sobre el paisaje salvaje. Pasado, presente y futuro podrían apreciarse entonces en el mismo paisaje, como capas replegadas que han ido construyendo el tiempo (caminos que se trazan sobre otros caminos trazados con anterioridad, al modo de un palimpsesto vial, rutero). Luego, el saber, tanto como verbo sustantivado o como acción, tiene una doble acepción o significación en el mismo poema. En la primera aparición: "Estaba quieto el camino/ el saber, en otra parte", diría relación con el conocimiento, la ciencia, la filosofía europeas, con el saber del imperio de turno. También hay aquí una lectura profética del pasado, pero posteriormente, se podría leer que no existe sólo una forma de saber: "tras la palabra hay un fruto/ en que duermen los que saben”. Esos que saben no serían los mismos portadores del saber que estaba "en otra parte". Esos que saben, conjugados en el presente, duermen. Esos que saben, sueñan. Navegan en una dimensión de inocencia: en la que “duermen los que saben/ al fin con sueño inocente”. Podríamos arriesgarnos y decir que el concepto de creación glissantiano podría sumar otro poder al de relación (integración) y diversidad (caos): el de inocencia, pero no la inocencia del que no sabe, más bien la inocencia del que sueña sin ataduras. Poder que es capaz de no forzar ni truncar un proceso de emancipación, pues no cabría en la fuerza de la inocencia ni la perversidad ni ninguna clase de colonialidad. Esos que sueñan podrían ser los antepasados que 
ayudan a construir, formar, en el presente -con su memoria, resistencias y polvo- el paisaje que (aún) nos rodea. Paisaje que crece. Esos que sueñan continúan presentes en ausencia, como fantasmas creadores desde planos que acaban, finalmente, incidiendo en lo físico y en lo venidero. $Y$ es en el sueño donde vida y muerte se ven entrelazadas en un limbo creador, momento donde se construye desde lo imposible una realidad posible. Es el lugar del desborde, donde la palabra creadora, barroca, no señala los límites, sino que se apasiona a crear tanto más diversidad y relaciones entre los paisajes internos y externos. Sin embargo, ese "sueño" inocente, frágil, intuitivo es justamente el que impediría seguir o dejarse arrastrar por aquel camino impuesto. De hecho, nos haría olvidar incluso que existe ese camino y ensancharía a nuestros pies la cartografía caótica de la realidad: los miles de senderos cuyas huellas desaparecen producto de la vegetación que (trans)forma la geografía. Senderos impredecibles que se interconectan permanentemente y que muchas veces no llevan a dirección conocida alguna. El poeta/árbol necesita del viento, cuyas partículas están hechas de palabras: "Falta el viento a quien es árbol". No obstante, detrás de cada palabra hay un fruto y, antes del fruto, predeciblemente un árbol alimentado de viento, es decir, de palabras. Así podríamos entender parte de lo que sigue ocultando el poema, el cual evidencia una interconexión recíproca, integradora de diversos elementos cuyo valor no superpone a uno sobre otro. Pero también se podría apreciar en esta lectura, el poder de otro concepto resignificado que anunciamos al principio y que no hemos tratado hasta aquí: el de reciprocidad. Es nuestro deseo desbordar el concepto clásico de reciprocidad, aquel que apela más bien a un intercambio económico de servicios o bienes, intentando cierto equilibrio, fuera del mercado. Sin abandonar la anterior conceptualización, comprendemos además que la reciprocidad está relacionada con la integración, el intercambio y el compromiso. Es una defensa de la solidaridad entre culturas. A lo anterior, hemos de sumar la urgencia de esta reciprocidad entre elementos, seres humanos y naciones, para, de esta manera, lograr sobrevivir a una historia hostil y reconocerse como un "todo" y, a la vez, reconocer todas las diferencias que enriquecen una comunión entre ese Todo-Mundo (en Glissant es frecuente la alusión al "cáliz" en varios de sus poemas, cuyo símbolo y uso también existió en los pueblos prehispánicos). No queremos idealizar el concepto de recipro- 
cidad, pues sabemos que aun cuando haya correspondencia y compromiso, la reciprocidad no carece de complejidad, de ambigüedad y fragilidad, de caos y falta de armonía. Como toda relación (fraterna o no), entre personas o pueblos o entre las islas de un archipiélago, lograr la integración deberá ser un proyecto de permanente intercambio de ideas, de culturas, de identidades, las que sostenidamente tiendan a la movilidad de una diversidad y la multiplicidad de las diferencias. Pero también deberá ser un proyecto que ampare el error y la impredecibilidad, que no demonice los conflictos, sino que visualice los aprendizajes que depara sus resoluciones, que contemple esperanzada la resistencia histórica, traumática:

Este continente, más que ninguna otra parte del mundo, ha sido, desde hace cuatro siglos, el lugar más vivaz y más extravagante en cuanto a una enorme experiencia, la de poner en contacto a casi todas las culturas conocidas, sus repulsiones mutuas y sus simbiosis nacientes (Glissant, 2002b).

Desde la geografía del Caribe se articula una teoría crítica compleja, deseuropeizada, devenida reflexiones y experiencias de nuestro propio subcontinente, una epistemología que se resiste a lo unitario, lo continental, el "espacio firme" del conocimiento. Esta epistemología se sabe frágil, cambiante y en vez de buscar validarse cientificistamente, asume una identidad movediza y es capaz de esculcar las heridas vivas que la colonia propinó e incluso intenta suturarlas, dejando de esconder bajo las ropas del discurso oficial los traumatismos que la historia oficial tampoco ha reconocido con el énfasis que merece. Esta epistemología integra aquel dolor y horror a una identidad, a la producción cultural, se integra a una danza a un verso, los que continuarán expandiendo poéticas ansiosas de re-conocer y difractar.

\section{Conclusiones}

Comenzaremos a cerrar este texto, con una demoledora cita del poeta y crítico de arte argentino, Aldo Pellegrini, que escribió por allá por los sesentas: 
La poesía tiene una puerta herméticamente cerrada para los imbéciles, abierta de par en par para los inocentes. No es una puerta cerrada con llave o con cerrojo, pero su estructura es tal que, por más esfuerzos que hagan los imbéciles, no pueden abrirla, mientras cede a la sola presencia de los inocentes. Nada hay más opuesto a la imbecilidad que la inocencia. La característica del imbécil es su aspiración sistemática de cierto orden de poder. El inocente, en cambio, se niega a ejercer el poder porque los tiene todos (1961, s/n).

En el proyecto de Glissant, la inocencia, como apreciamos en "1953”, posee un carácter subversivo, antípoda de la depravación y violencia que se alimenta del poder. En el poema, esta vincula la inocencia con el sueño, con una suerte de ideal de no perversión, siempre vinculada esta a la “aspiración sistemática de cierto orden de poder", como escribe Pellegrini. Debido a esto, la poesía no debería ser anestesiada y derivada a la tanatología de una crítica que ha cerrado bajo llave el ingreso de otras formas de comprender y que, incluso a veces se ha empeñado en legitimar un discurso postcolonialista (en líneas como subalternidad, fronteras, etc.), pero que afanosamente busca legitimarse en el mercado crítico a través de las herramientas que se heredaron de la colonia y que subsisten consagradamente. En cambio Glissant, al resistir, pero no desechar pensamientos no 'propios', logra encontrar una puerta de salida a este peligroso pensamiento descolonizador-postcolonialista que se ha pontificado como la voz autorizada. Se inscribe además con conceptos que evitarían esta dictadura de Europa sobre todo pensamiento y/o texto nacido en el Todo-Mundo. Pero si nos relacionamos con esta teoría y si nos tomamos la diversidad y la integración y la reciprocidad y proyectamos y exigimos una transdisciplinariedad del conocimiento, por ejemplo, y estudiamos y repensamos culturas, fenómenos o, como ahora, textos líricos, la misma poesía podría ser leída a través de cada una de las manifestaciones presentes en el Todo-Mundo, gesto que es emancipatorio en el análisis e insurrecto en la educación de una resistencia. La propia ciencia podría suscitar una relación entre la geografía (paisaje), la física (teoría del caos), el arte (pintura), la lingüística, la política, la botánica (rizoma), las matemáticas (fractal), la literatura y muchas otras y más productivas relaciones. Y no es mera especulación, ya que para Glissant la poesía es el movimiento que articula la relación entre el plano físico y el temporal, entre el paisaje y la historia, a través de la 
palabra creadora, barroca. Ante ello, toda manifestación humana tendría cabida y poder si accede a las puertas, si se vincula con la poesía, la literatura, la cultura, con una actitud de inocencia, al decir de Pellegrini, y con la actitud apasionada de Glissant en relación al conocimiento. Así, serán por distintos senderos los accesos a la poesía, a la ciencia, al conocimiento, los cuales se emanciparán, transdisciplinarios. Lamentablemente hasta hoy, lo más común es que se desarrolle un solipsismo disciplinario, en palabras de Lewis Gordon (2011), es decir, la creencia de que una sola mirada o disciplina cubre comprensivamente toda la realidad; a lo más, se llega a una relación de interdisciplinariedad, donde cada disciplina se considera autosuficiente. Mientras tanto, un discurso “descolonizador" continuará blandiendo armas de Occidente, en universidades e instituciones del saber, luchando por minúsculas cuotas de poder, organizando y embelleciendo su silencio. Para cerrar, esta "epistemología poética" apostada no solo amplía coherentemente el pensamiento de Glissant, sino que resiste genuinamente la colonialidad del saber, del pensar, del hacer y del ser en el mundo, resistencia que lejos de quemar las naves enemigas, articula una comprensión del "Todo-Mundo" emancipando redes de asociación, integrando saberes, conocimientos, ideologías que movilizan una epistemología que no excluye, ni violenta ni adecua sino que activa vínculos, que tensa y exhorta reciprocidades mientras comprende y procura transformar el dinámico paisaje de la cultura y la historia. Que exhorta inevitablemente un diálogo entre los saberes humanos, propiciando una transdisciplinariedad, una relación y proyección intensa de saberes, fenómenos, obras, sujetos, paisajes, historicidades que integrarán el conocimiento humano futuro.

\section{Referencias}

Anónimo (2002). Popol Vuh. Barcelona: Red Ediciones S.L.

Ávila Pacheco, V. M. (2010). Representaciones bifurcadas en tiempos de futuro: De la colonialidad a la decolonialidad. En http://www.unilibre.edu.co/ dialogos/admin/upload/uploads/Articulo\%206.pdf

Bansart, A. (S/F) "Édouard Glissant". En http://cimarronajesss.blogspot. com/2011/o2/edouard-glissant-por-andres-bansart.html

Boyer, A. (2009). ARCHIPELIA. Lugar de la relación entre (geo)estética y poética. Nómadas, 31, 13-25. 
Glissant, É. (1965). Les indes. Un champ d'̂̀les La terre inquiète. Paris: Éditions du Seuil.

. (1969). La intención poética. París: Éditions du Seuil.

. (1990). Poétique de la relation. Paris: Gallimard.

. (2002a). Introducción a una poética de lo diverso. Barcelona: Ed. del Bronce.

. (2002b). Las Américas barrocas. En http://www.resonancias.org/content $/ \mathrm{read} / 238 /$.

. (2004). Sol de la conciencia. Barcelona: El Cobre.

. (2005). El discurso antillano. Caracas: Monte Ávila Editores. . (2006). Tratado del Todo-Mundo. Barcelona: El Cobre.

Gordon, L. R. (2011). Manifiesto de transdisciplinariedad. Para no volvernos esclavos del conocimiento de otros. Traspasando fronteras, 1, 7-11.

Kohan, N. (2003). Marx en su (Tercer) Mundo. Hacia un socialismo no colonizado. La Habana: Centro de Investigación y Desarrollo de la Cultura Cubana Juan Marinello.

Maignan-Claverie, Ch. (2003). D’une vision à une écriture archipélique. En Georges Voisset (Dir), L’imaginaire de l'archipel (pp. 339-352). Paris: Karthala.

Marramao, G. (1998). Cielo y tierra. Genealogía de la secularización. Barcelona: Editorial Paidós.

Mazeau, P. (2005). Algunas reflexiones sobre la poética de la relación de Édouard Glissant. Contexto: Revista Anual de Estudios Literarios, 11, 71-84.

Mercier, C. (2012). Esbozo de una poética del paisaje en la obra novelesca de Édouard Glissant. Anales de Filología Francesa, 20, 173-185.

Pellegrini, A. (1961). Se llama poesía todo aquello que cierra la puerta a los imbéciles. Poesía = Poesía, 9. Disponible en: http://www.lamaquinadeltiempo.com/prosas/pellegrini1.htm

Said, E. (2006). El mundo, el texto y el crítico. Barcelona: Debate.

Sancholuz, C. (2002-2003). La construcción del área cultural caribeña. Los aportes de Édouard Glissant a partir de Les discourses antillais. Orbis Tertius, VIII (9), 1-9. 